\title{
Is omega-3 key to unlocking inflammation in obesity?
}

\author{
P. J. White • A. Marette
}

Published online: 7 July 2006

(C) Springer-Verlag 2006

Low-grade inflammation has been identified as a key player in the development of the metabolic syndrome in obese subjects, leading the way to type 2 diabetes and cardiovascular diseases. Insulin resistance, a primary component of the metabolic syndrome, is characterised by chronically elevated concentrations of proinflammatory cytokines, acute phase proteins, and enhanced activation of proinflammatory signalling in insulin-responsive tissues of obese subjects.

The research effort thus far has established that, in obesity, the expanding adipose tissue makes a substantial contribution to the development of obesity-linked inflammation via the secretion of various proinflammatory cytokines, chemokines and adipokines. Recent investigations into the mechanisms responsible for this phenomenon have outlined a role for the macrophage [1-3]. In fact, macrophage accumulation in adipose tissue is positively correlated with adipocyte size and contributes to the expression of proinflammatory mediators of insulin resistance, such as TNF- $\alpha$, IL-6 and inducible nitric oxide synthase (iNOS) $[1,2]$. Furthermore, both inhibition of macrophage function, via myeloid-specific IKB kinase- $\beta$ deletion [3], and prevention of macrophage accumulation in adipose tissue, via deletion of $\mathrm{C}-\mathrm{C}$ motif chemokine receptor-2 [4], prevent the development of the inflammatory phenotype and insulin resistance with obesity. Hence, there is growing support for the current notion that

P. J. White $\cdot$ A. Marette $(\bowtie)$

Department of Anatomy-Physiology and Lipid Research Unit, Laval University Hospital Research Centre,

2705 Laurier Blvd,

G1V 4G2 Ste-Foy, QC, Canada

e-mail: andre.marette@crchul.ulaval.ca macrophage infiltration into adipose tissue is central to obesity-related metabolic disorders.

Pioneering work by Storlien and colleagues has shown that long-chain omega-3 polyunsaturated fatty acids ( $\mathrm{LC} n-$ 3PUFA) can prevent the development of diet-induced insulin resistance in rats [5]. Furthermore, a growing number of studies support a link between this beneficial effect of LCn-3PUFA and an anti-inflammatory mechanism. LCn-3PUFA have been widely reported to have antiinflammatory effects in a range of chronic inflammatory conditions, including rheumatoid arthritis and Crohn's disease $[6,7]$. Treatment of obese subjects with $\mathrm{LCn}^{-}$ 3PUFA in a clinical setting has also been shown to reduce circulating levels of both proinflammatory cytokines and acute phase proteins $[8,9]$. Whether these anti-inflammatory actions of LCn-3PUFA, and their positive influence on the metabolic syndrome, can be linked to local blunting of adipose tissue inflammation is not yet known.

In this issue of Diabetologia, Todoric et al. [10] present evidence that the inclusion of LCn-3PUFA in a high-fat diet prevents the development of an inflammatory gene expression profile and macrophage infiltration in the adipose tissue of obese diabetic $d b / d b$ mice. Despite significantly enhancing weight gain, LCn-3PUFA treatment completely prevented the diet-induced adipose tissue switch to an inflammatory profile, attenuating the upregulation of an array of genes, notably those encoding the macrophage surface marker CD68, macrophage chemotactic protein-1, and the lipopolysaccharide receptor CD14. Incorporation of LCn-3PUFA into the high-fat diet also prevented the downregulation of genes involved in lipid metabolism, including those for fatty acid synthase and hormone-sensitive lipase, in adipose tissue of the obese mice. The anti-inflammatory effect of $\mathrm{LC} n-3$ PUFA was related to greatly diminished macrophage migration into 
adipose tissue and substantially enhanced circulating adiponectin levels. n-3PUFA as part of the high-fat diet also lowered circulating triglyceride to levels below those seen in chow-fed mice. Although these data suggest that improvement of metabolic status in obesity by LCn-3PUFA involves regulation of the adipose tissue gene expression profile and the prevention of macrophage infiltration into fat depots, further research is required to elucidate the exact mechanisms responsible.

Indeed, there are a multitude of potential mechanisms that could account for the anti-inflammatory actions elicited by LCn-3PUFA in this study (Fig. 1). For example, the competitive inhibition of arachidonate-derived proinflammatory leukotriene and prostaglandin production by LC $n-3$ PUFA [11-13] could limit inflammation in adipose tissue. Negative modulation of monocyte function by LCn-3PUFA [14] could also account for the reduced macrophage infiltration. Interestingly, more recent studies have also identified LCn-3PUFA as precursors of two novel families of potent anti-inflammatory lipid mediators, the resolvins and protectins [15]. We may conjecture that these eicosanoids could contribute to the LCn-3PUFAmediated inhibition of adipose tissue inflammation reported by Todoric and colleagues by favouring the resolution of the inflammatory process. Alternatively, LC $n-3$ PUFA may blunt adipose tissue inflammation by acting as endogenous ligands for the peroxisome proliferator-activator receptors (PPARs) $\alpha, \delta$ and $\gamma$, which have recently been recognised for their anti-inflammatory actions in adipocytes and macrophages [16-20].

Of the three known mammalian PPAR isoforms, $\mathrm{LC}^{-}$ 3PUFA appear to bind most efficiently with PPAR $\gamma$ [21].
On the basis of current literature, this latter target of $\mathrm{LCn}^{-}$ 3PUFA appears to be the most plausible mechanistic explanation for the findings of Todoric and colleagues. Accordingly, PPAR $\gamma$ agonists have been reported to inhibit macrophage activation [22] and infiltration into adipose tissue [2]. Moreover, a very recent study using the PPAR $\gamma$ inhibitor bisphenol A diglycidyl ether (BADGE) demonstrated that treatment with LCn-3PUFA augments circulating adiponectin levels via a PPAR $\gamma$-dependent mechanism [17]. Given that adiponectin is known to exert antiinflammatory effects and enhance insulin sensitivity [23, 24], it is conceivable that LCn-3PUFA could impede the adipose tissue switch to an inflammatory gene expression profile in response to obesity via a PPAR $\gamma$ - and adiponectindependent mechanism.

In accord with this theory, the use of PPAR $\gamma$ agonists is characterised by enhanced weight gain [25] similar to that seen with LCn-3PUFA treatment in this study. However, it should be noted that not all studies using LCn-3PUFA reported increased weight gain. Indeed, to the contrary, the prevention of weight gain in insulin resistance prevention studies is often reported following treatment with $\mathrm{LCn}-$ 3PUFA [26]. This heterogeneity as regards the influence of $\mathrm{LC} n$-3PUFA on weight gain may stem from differences in the animal models used, the mode of treatment (e.g. use for prevention or reversal of insulin resistance), or might result from differential degrees of LCn-3PUFA signalling through the PPAR $\gamma$ and PPAR $\alpha$ receptors in these studies [25].

In conclusion, these mechanisms remain to be explored and it is very likely that the results presented in the article by Todoric and colleagues reflect a combination of the pleiotropic functions of $\mathrm{LC} n$-3PUFA at multiple sites within the adipose
Fig. 1 Proposed mechanisms for the anti-inflammatory actions of LCn-3PUFA in adipose tissue. $C O X$ Cyclooxygenase, $P G E$ prostaglandin, $L O X$ 5-lipoxygenase, $L T B$ leukotriene

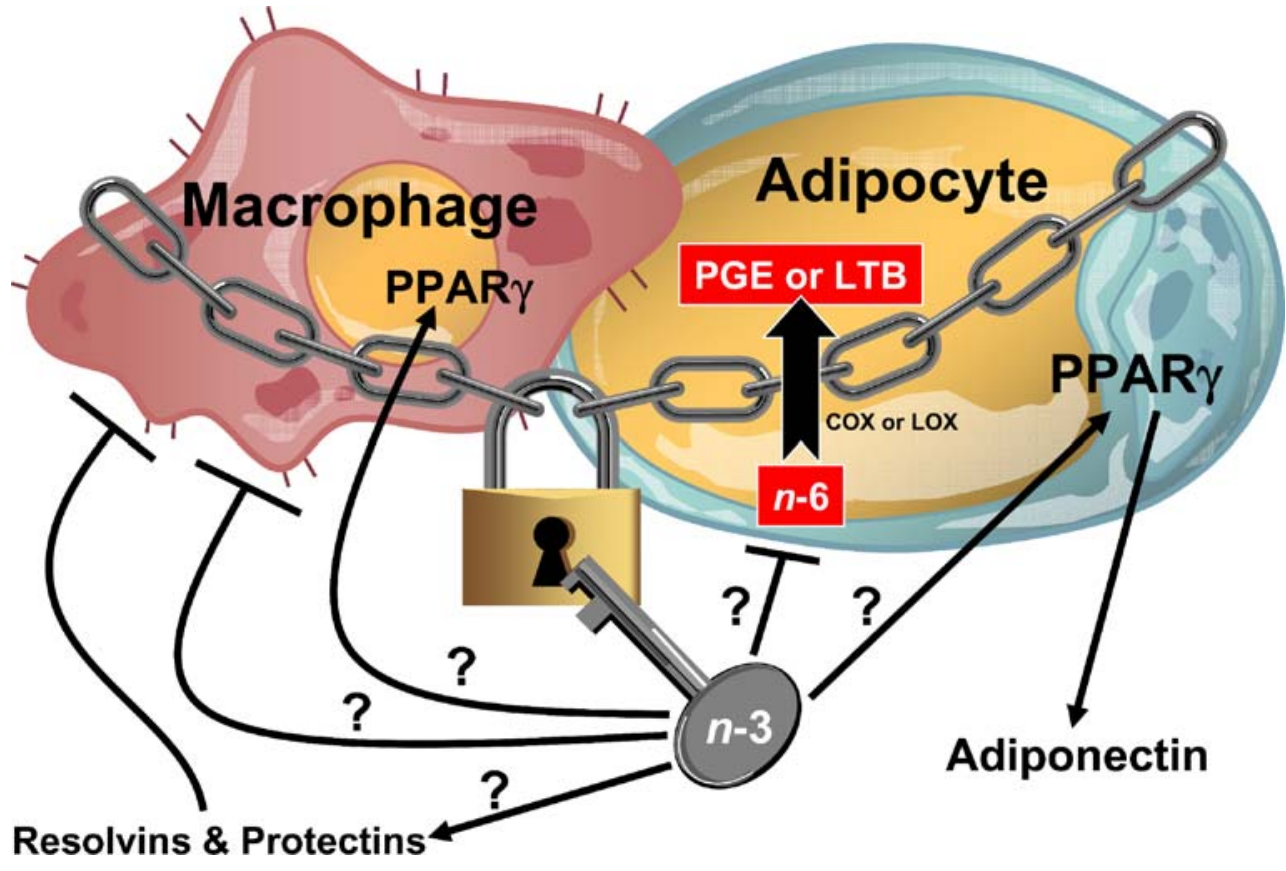


tissue. Additional studies are certainly warranted to examine whether such effects of LCn-3PUFA are present in other insulin-sensitive tissues, including liver and skeletal muscle, and to elucidate the underlying mechanisms. It now seems critical to determine whether the adipose-specific blunting of an inflammatory profile is the principal mechanism by which LC $n-3$ PUFA prevent diet-induced insulin resistance.

Acknowledgement A. Marette is the recipient of a CIHR Investigator Award and is a National Researcher of the Fonds de la Recherche en Santé du Québec.

\section{References}

1. Weisberg SP, McCann D, Desai M, Rosenbaum M, Leibel RL, Ferrante AW Jr (2003) Obesity is associated with macrophage accumulation in adipose tissue. J Clin Invest 112:1796-1808

2. Xu H, Barnes GT, Yang Q et al (2003) Chronic inflammation in fat plays a crucial role in the development of obesity-related insulin resistance. J Clin Invest 112:1821-1830

3. Arkan MC, Hevener AL, Greten FR et al (2005) IKK-beta links inflammation to obesity-induced insulin resistance. Nat Med 11:191-198

4. Weisberg SP, Hunter D, Huber R et al (2006) CCR2 modulates inflammatory and metabolic effects of high fat feeding. $\mathrm{J}$ Clin Invest 116:115-124

5. Storlien LH, Kraegen EW, Chisholm DJ, Ford GL, Bruce DG, Pascoe WS (1987) Fish oil prevents insulin resistance induced by high-fat feeding in rats. Science 237:885-888

6. Geusens P, Wouters C, Nijs J, Jiang Y, Dequeker J (1994) Long term effect of omega-3 fatty acid supplementation in active rheumatoid arthritis. A 12 month, double blind, controlled study. Arthritis Rheum 37:824-829

7. Belluzzi A, Brignola C, Campieri M, Pera A, Boschi S, Miglioli M (1996) Effect of an enteric-coated fish-oil preparation on relapses in Crohn's disease. N Engl J Med 334:1557-1560

8. Rallidis LS, Paschos G, Liakos GK, Velissaridou AH, Anastasiadis G, Zampelas A (2003) Dietary $\alpha$-linolenic acid decreases C-reactive protein, serum amyloid A and interleukin-6 in dyslipidaemic patients. Atherosclerosis 167:237-242

9. Trebble T, Arden NK, Stroud MA et al (2003) Inhibition of tumour necrosis factor- $\alpha$ and interleukin 6 production by mononuclear cells following dietary fish-oil supplementation in healthy men and response to antioxidant co-supplementation. Br J Nutr 90:405-412

10. Todoric J, Löffler M, Huber $J$ et al (2006) Adipose tissue inflammation induced by high-fat diet in obese diabetic mice is prevented by $n-3$ polyunsaturated fatty acids. Diabetologia DOI 10.1007/s00125-006-0300-x

11. Lee TH, Mencia-Huerta JM, Shih C, Corey EJ, Lewis RA, Austen KF (1984) Effects of exogenous arachidonic, eicosapentaenoic, and docosahexaenoic acids on the generation of 5-lipoxygenase pathway products by ionophore-activated human neutrophils. J Clin Invest 74:1922-1933

12. Needleman P, Raz A, Minkes MS, Ferrendelli JA, Sprecher H (1979) Triene prostaglandins: prostacyclin and thromboxane biosynthesis and unique biological properties. Proc Natl Acad Sci U S A 76:944-948

13. Corey EJ, Shih C, Cashman JR (1983) Docosahexaenoic acid is a strong inhibitor of prostaglandin but not leukotriene biosynthesis. Proc Natl Acad Sci U S A 80:3581-3584

14. Hughes DA (1998) In vitro and in vivo effects of $n^{-3}$ polyunsaturated fatty acids on human monocyte function. Proc Nutr Soc 57:521-525

15. Bannenberg GL, Chiang N, Ariel A et al (2005) Molecular circuits of resolution: formation and actions of resolvins and protectins. J Immunol 174:4345-4355

16. Kliewer SA, Sundseth SS, Jones SA et al (1997) Fatty acids and eicosanoids regulate gene expression through direct interactions with peroxisome proliferator-activated receptors $\alpha$ and $\gamma$. Proc Natl Acad Sci U S A 94:4318-4323

17. Neschen S, Morino K, Rossbacher JC et al (2006) Fish oil regulates adiponectin secretion by a peroxisome proliferatoractivated receptor- $\gamma$-dependent mechanism in mice. Diabetes 55:924-928

18. Pilon G, Dallaire P, Marette A (2004) Inhibition of inducible nitric-oxide synthase by activators of AMP-activated protein kinase: a new mechanism of action of insulin-sensitizing drugs. J Biol Chem 279:20767-20774

19. Lee $\mathrm{CH}$, Chawla A, Urbiztondo $\mathrm{N}$ et al (2003) Transcriptional repression of atherogenic inflammation: modulation by PPAR $\delta$. Science 302:453-457

20. Tsuchida A, Yamauchi T, Takekawa S et al (2005) Peroxisome proliferator-activated receptor (PPAR) $\alpha$ activation increases adiponectin receptors and reduces obesity-related inflammation in adipose tissue: comparison of activation of PPAR $\alpha, \operatorname{PPAR} \gamma$, and their combination. Diabetes 54:3358-3370

21. Xu HE, Lambert MH, Montana VG et al (1999) Molecular recognition of fatty acids by peroxisome proliferator-activated receptors. Mol Cell 3:397-403

22. Ricote M, Li AC, Willson TM, Kelly CJ, Glass CK (1998) The peroxisome proliferator activated receptor- $\gamma$ is a negative regulator of macrophage activation. Nature 319:79-82

23. Berg AH, Combs TP, Du X, Brownlee M, Scherer PE (2001) The adipocyte-secreted protein Acrp30 enhances hepatic insulin action. Nat Med 7:947-953

24. Yamauchi T, Kamon J, Waki H et al (2001) The fat derived hormone adiponectin reverses insulin resistance associated with both lipoatrophy and obesity. Nat Med 7:941-946

25. Carmona MC, Louch K, Nibbelink M et al. (2005) Fenofibrate prevents rosiglitazone-induced body weight gain in $o b / o b$ mice. Int J Obes 29:864-871

26. Wang H, Storlien LH, Huang XF (2002) Effects of dietary fat types on body fatness, leptin, and ARC leptin receptor, NPY, and AgRP mRNA expression. Am J Physiol Endocrinol Metab 282: E1352-E1359 